\title{
Correlation between clinical and electrophysiological findings of carpal tunnel syndrome
}

\begin{abstract}
Objective: correlate between clinical and electrophysiological findings of carpal tunnel syndrome

Methods: cross sectional study at outpatient setting. 109 patients (83females, 26males) with clinical manifestations of carpal tunnel syndrome participated in the study.

All the patients had the following: Medical history and neurological examination including Tinel's sign and Phalen test and nerve conduction studies including medianulnar, median -radial comparative studies and electromyography of both upper extremities.
\end{abstract}

Results: mean age $57.71 \pm 13.4$. pain was mild in $9.2 \%$, moderate in $25.7 \%$ and severe in $56 \%$ of patients. Numbness was present in $87.2 \%$. Impaired sensory exam in $43.1 \%$ Impaired motor exam in $8.3 \%$. Positive Tinel's sign unilateral $(38.5 \%)$ and bilateral (47.7\%). Positive Phalen test unilateral (30.3\%) and bilateral (34.9\%). Unilateral thenar Muscle wasting in $4.6 \%$ and bilateral in $1.8 \%$. Pure sensory median neuropathy was found in 65 patients $(59.6 \%)$, sensory motor median neuropathy in 44 patients $(40.37 \%)$. Demyelinating neuropathy in $91.7 \%$ and demyelinating-axonal neuropathy in $8.3 \%$ of patients.

Abnormal distal motor latency was significantly correlated with severity of pain $\mathrm{p}=0.0025$, impaired sensory exam $\mathrm{p}=0.0001$, impaired motor exam $\mathrm{p}=0.0001$, positive Tinel's sign of both hands $\mathrm{p}=0.0001$, positive Phalen test of both hands $\mathrm{p}=0.0001$. as well as with unilateral or bilateral muscle wasting $\mathrm{p}=0.001$.

Prolonged peak median sensory latency was significantly correlated with numbness $p=0.0001$, severity of pain $p=0.001$, Impaired sensory exam $p=0.005$, positive Tinel's sign for either one or both hands $\mathrm{p}=0.0001$, positive Phalen test of one or both hands $\mathrm{p}=0.0001$

Conclusion: Highly significant correlation was found between subjective and objective sensory manifestation and peak median sensory latency. While distal motor latency were significantly correlated with severe pain, only bilateral positive Tinel's sign and Bilateral Phalen test and the objective sensory and motor deficit.

Keywords: carpal tunnel syndrome, phalen, tinel, nerve conduction tests
Volume 4 Issue 3 - 2018

\author{
Naglaa Hussein,' Thochyovny Desmarets, \\ Mohammad Seth, ${ }^{3}$ Richard Vilchez ${ }^{2}$ \\ 'Attending Physiatrist at Montefiore Medical Center,Albert \\ Einstein College of Medicine, NY, Assistant Professor of \\ Physical Medicine, Rheumatology and Rehabilitation, Alexandria \\ University, Egypt \\ ${ }^{2}$ Clinical Assistant at Essen Medical Associate, USA \\ ${ }^{3}$ Department of Internal Medicine Resident PGY, Berkshire \\ Medical Center, USA
}

Correspondence: Naglaa Hussein, Attending Physiatrist at Montefiore Medical Center, Albert Einstein College of Medicine, NY,Assistant Professor of Physical Medicine, Rheumatology and Rehabilitation, Alexandria University, Egypt, Email nagla_kashif@hotmail.com

Received: May 01, 2018 | Published: May 29, 2018

\section{Introduction}

Carpal tunnel syndrome (CTS) is one of the most common upper limb entrapment neuropathies. It constitutes approximately $90 \%$ of all entrapment neuropathies. ${ }^{1}$ It is the result of squeezing or compression of median nerve at the carpal tunnel. An estimated one million adults from the united states annually have CTS requiring medical treatment with high cost burden on health care system., ${ }^{1,2}$

The incidence and prevalence vary $0.125 \%-1 \%$ and $5-16 \%$ depending upon the criteria used for the diagnosis. ${ }^{1-8}$ Carpal tunnel syndrome is more prevalent among middle aged female with peak incidence around 55-60 years. ${ }^{1,2,59}$

Carpal tunnel syndrome presents clinically with variable symptoms depend on the severity of the disease. These symptoms include numbness, tingling, burning and pain in the hand predominantly, in the thumb, index, middle and lateral half of ring finger. The pain or tingling may travel up the forearm toward the shoulder. In addition to weakness, clumsiness of the hands. ${ }^{1}$
Several clinical tests have been described to aid in the diagnosis of CTS. None of these tests are diagnostic on their own. Most of these tests complement the diagnosis of CTS. Tinel's sign is one the diagnostic tests for CTS. Tinel described this sign in $1915 .{ }^{10}$ It is not a precise test. Several factors can influence the outcome of the test. It is reported to be associated with sensitivities $23-67 \%$ and specificities of $55 \%$ to $100 \% .{ }^{11-14} \mathrm{Phalen}$ 's test is another test described in $1957 .{ }^{15} \mathrm{The}$ reported sensitivity ranges between $10 \%-91 \%$ and specificity between $33 \%-100 \%$. ${ }^{11,12,16-20}$

Electro diagnostic testing can be helpful to confirm or exclude CTS when the clinical diagnosis is uncertain..$^{21}$ It is also useful to determine the severity of nerve compression and to assist in decision regarding surgical intervention. ${ }^{21}$

The combination of characteristic symptoms and signs and confirmatory testing appears to be most accurate for the diagnosis of CTS. ${ }^{22,23}$

The aim of the study was to correlate between clinical and electrophysiological findings of carpal tunnel syndrome 


\section{Patients and methods}

This was cross sectional study at outpatient setting. A total of 104 patients who had symptoms of pain, paresthesia and /or weakness in their hands during the period of Augst, 2016 till July, 2017 were included to the study. Exclusion criteria were polyneuropathy signs and symptoms, cervical radiculopathy or any other neurological or neuromuscular disease. The following data were recorded from all the included patients after signing informed consent for participation in the study; Medical history, pain scale using visual analogue scales (VAS) from $0-10$, where 0 means no pain, 10 means severe pain. presence or absence of numbness of the hands, detailed neurological examination including wasting of thenar muscles, the presence of impaired sensory examination, presence of impaired motor examination by manual muscle testing, Tinel's $\operatorname{sign}^{10}$ and Phalen test ${ }^{15}$ and electrophysiological testing.

All the patients had the following electrophysiologic tests: ${ }^{24}$

Nerve conduction studies(NCS) for both upper extremities including;

i. Median motor conduction study recording from abductor pollicis brevis while stimulating at the wrist and elbow.

ii. Ulnar motor conduction study recording from abductor digiti minimi while stimulating at wrist and at the elbow above and below the ulnar groove.

iii. Median and ulnar F wave responses.

iv. Median sensory response recording from digit two while stimulating the wrist.

v. Ulnar sensory response recording from digit five while stimulating the wrist

vi. Radial sensory response recording snuffbox, stimulating over lateral radius.

vii. Additional comparative studies; median-ulnar digit four sensory latencies, median -radial digit one sensory latencies were conducted in case of normal routine NCS

viii. Needle electromyography (EMG) of both upper extremities; muscles tested: Abdactor pollicis brevis, first dorsal interosseous, pronator teres, biceps, triceps, deltoid, extensor digitorm communis, and cervical paraspinal muscles.

Electrophysiological severity of CTS was classified as mild, moderate and severe according to the following criteria. Mild CTS was determined as prolongation of distal latency and decrease in the amplitude of median sensory nerve. Moderate CTS was determined as in addition to mild CTS criteria prolongation of distal latency of median motor nerve. Severe CTS was determined as no record of sensory potential, prolongation of distal latency and decrease in amplitude of median motor nerve..$^{25}$

\section{Statistical analysis}

The Data was collected and entered into the personal computer. Statistical analysis was done using Statistical Package for Social Sciences (SPSS/version 21) software. Descriptive statistics were done for quantitative data as minimum\& maximum of the range as well as mean \pm SD (standard deviation) for quantitative parametric data, while it was done for qualitative data as number and percentage.
Inferential analyses for independent variables were done using Chi square test for differences between proportions and Fisher's exact test for variables with small expected numbers.

\section{Results}

mean age $57.71 \pm 13.4 .14$ patients had unilateral CTS $(12.84 \%)$ and 95 patients had bilateral CTS $(87.16 \%)$. Table 1 shows demographic and clinical data. Pain was severe in $56 \%$ of patients. Numbness was present in $87.2 \%$. Impaired sensory exam in $43.1 \%$, Impaired motor exam in $8.3 \%$. Positive Tinel's sign unilateral $(38.5 \%)$ and bilateral (47.7\%). Positive Phalen test unilateral (30.3\%) and bilateral (34.9\%). Unilateral thenar Muscle wasting in $4.6 \%$ and bilateral in $1.8 \%$. Table 2 demonstrates NCS findings, while Table $3 \&$ Table 4 shows the relationship between motor distal latency and peak sensory latency and clinical findings respectively. Table $5 \&$ Table 6 demonstrate the relation between pain scale and distal motor latency and peak sensory latency respectively.

Table I Demographic and clinical data of the studied patients group

\begin{tabular}{|c|c|c|}
\hline & Number & Percent \\
\hline $\begin{array}{l}\text { Age } \\
<50 \\
50- \\
60- \\
70+\end{array}$ & $\begin{array}{l}29 \\
37 \\
26 \\
17\end{array}$ & $\begin{array}{l}26.6 \\
33.9 \\
23.9 \\
15.6\end{array}$ \\
\hline $\begin{array}{l}\text { Range } \\
\text { Mean } \pm \text { S.D. }\end{array}$ & $\begin{array}{l}28-90 \\
57.7 \pm 13.4\end{array}$ & \\
\hline $\begin{array}{l}\text { Sex } \\
\text { Male } \\
\text { Feamle }\end{array}$ & $\begin{array}{l}26 \\
83\end{array}$ & $\begin{array}{l}23.9 \\
76.1\end{array}$ \\
\hline $\begin{array}{l}\text { Pain scale } \\
\text { No } \\
\text { Mild } \\
\text { Moderate } \\
\text { Severe }\end{array}$ & $\begin{array}{l}10 \\
10 \\
28 \\
61\end{array}$ & $\begin{array}{l}9.2 \\
9.2 \\
25.7 \\
56.0\end{array}$ \\
\hline Numbness (positive) & 95 & 87.2 \\
\hline \multicolumn{3}{|l|}{ Sensory exam } \\
\hline Intact & 62 & 56.9 \\
\hline Impaired & 47 & 43.1 \\
\hline \multicolumn{3}{|l|}{ Motor exam } \\
\hline Intact & 100 & 91.7 \\
\hline Impaired & 9 & 8.3 \\
\hline \multicolumn{3}{|l|}{ Tinnel's sign } \\
\hline No & 15 & 13.8 \\
\hline One hand & 42 & 38.5 \\
\hline Both hands & 52 & 47.7 \\
\hline \multicolumn{3}{|l|}{ Phalen's test } \\
\hline No & 38 & 34.9 \\
\hline One hand & 33 & 30.3 \\
\hline Both hands & 38 & 34.9 \\
\hline \multicolumn{3}{|l|}{ Muscle wasting } \\
\hline No & 102 & 93.6 \\
\hline One hand & 5 & 4.6 \\
\hline Both hands & 2 & 1.8 \\
\hline
\end{tabular}

Abnormal distal motor latency was significantly correlated with severity of pain $p=0.0025$, impaired sensory exam $p=0.0001$, impaired motor exam $p=0.0001$, positive Tinel's sign of both hands $p=0.0001$, 
positive Phalen test of both hands $p=0.0001$. As well as with unilateral or bilateral muscle wasting $\mathrm{p}=0.001$.

Table 2 Nerve conduction studies (NCS) and EMG findings in the studied group

\begin{tabular}{lll}
\hline & Number & Percent \\
\hline $\begin{array}{l}\text { NCS showing pure sensory neuropathy } \\
\text { One hand }\end{array}$ & 14 & 12.84 \\
Both hands & 51 & 46.8 \\
NCS showing sensorimotor neuropathy & & \\
$\begin{array}{l}\text { One hand } \\
\text { Both hands }\end{array}$ & 7 & 6.4 \\
NCS and EMG showing demyelinating & 37 & 33.9 \\
neuropathy & & \\
$\begin{array}{l}\text { One hand } \\
\text { Both hands }\end{array}$ & 17 & 15.6 \\
NCs and EMG showing demyelinating - & 83 & 76.1 \\
axonal neuropathy & & \\
$\begin{array}{l}\text { One hand } \\
\text { Both hands }\end{array}$ & 4 & 3.7 \\
\hline
\end{tabular}

Table 3 Relation between motor distal latency and clinical signs and symptoms

\begin{tabular}{|c|c|c|c|c|c|}
\hline & & & Motor dis & al latency & \\
\hline & & & $\begin{array}{l}\text { Normal } \\
\text { " } n=65\end{array}$ & $\begin{array}{l}\text { Abnormal } \\
\text { "n=44" }\end{array}$ & $\mathbf{P}$ \\
\hline & & No. & 60 & 35 & \\
\hline Numbnecs & Present & $\%$ & $81.1 \%$ & $100.0 \%$ & 003 \\
\hline TNumintess & & No. & 14 & 0 & (003 \\
\hline & Absent & $\%$ & $18.9 \%$ & $0.0 \%$ & \\
\hline & Intact & No. & 61 & 1 & \\
\hline Sensory & & $\%$ & $82.4 \%$ & $2.9 \%$ & $00001 *$ \\
\hline exam & Impaired & No. & 13 & 34 & 0.0001 \\
\hline & & $\%$ & $17.6 \%$ & $97.1 \%$ & \\
\hline & Intact & No. & 74 & 26 & \\
\hline Motor & & $\%$ & $100.0 \%$ & $74.3 \%$ & $0.0001 *$ \\
\hline exam & Impaired & No. & 0 & 9 & \\
\hline & & $\%$ & $0.0 \%$ & $25.7 \%$ & \\
\hline & No & No. & 15 & 0 & \\
\hline & & $\%$ & $20.3 \%$ & $0.0 \%$ & \\
\hline Tinnel's & One hand & No. & 42 & 0 & م00مו* * \\
\hline sign & & $\%$ & $56.8 \%$ & $0.0 \%$ & 0.0001 \\
\hline & Both hands & No. & 17 & 35 & \\
\hline & & $\%$ & $23.0 \%$ & $100.0 \%$ & \\
\hline & No & No. & 38 & 0 & \\
\hline & & $\%$ & $51.4 \%$ & $0.0 \%$ & \\
\hline & One hand & No. & 33 & 0 & \\
\hline $\begin{array}{l}\text { Phalen's } \\
\text { test }\end{array}$ & & $\%$ & $44.6 \%$ & $0.0 \%$ & $0.0001 *$ \\
\hline & Both hands & No. & 3 & 35 & \\
\hline & & $\%$ & $4.1 \%$ & $100.0 \%$ & \\
\hline & No & No. & 74 & 28 & \\
\hline & & $\%$ & $100.0 \%$ & $80.0 \%$ & \\
\hline Muscle & One hand & No. & 0 & 5 & $0001 *$ \\
\hline wasting & & $\%$ & $0.0 \%$ & $14.3 \%$ & 0.001 \\
\hline & Both hands & No. & 0 & 2 & \\
\hline & & $\%$ & $0.0 \%$ & $5.7 \%$ & \\
\hline
\end{tabular}

Table 4 Relation between peak median sensory and clinical signs and symptoms.

\begin{tabular}{|c|c|c|c|c|c|}
\hline & & & \multicolumn{2}{|c|}{ Peak median sensory } & \multirow[b]{2}{*}{$\mathbf{P}$} \\
\hline & & & $\begin{array}{l}\text { Normal } \\
\text { "n= I3" }\end{array}$ & $\begin{array}{l}\text { Abnormal } \\
n=96\end{array}$ & \\
\hline \multirow{4}{*}{ Numbness } & \multirow{2}{*}{ Present } & No. & 5 & 90 & \multirow{4}{*}{$0.000 I^{*}$} \\
\hline & & $\%$ & $38.5 \%$ & $93.8 \%$ & \\
\hline & \multirow{2}{*}{ Absent } & No. & 8 & 6 & \\
\hline & & $\%$ & $61.5 \%$ & $6.2 \%$ & \\
\hline \multirow{4}{*}{ Sensory exam } & \multirow{2}{*}{ Intact } & No. & 12 & 50 & \multirow{4}{*}{$0.005 *$} \\
\hline & & $\%$ & $92.3 \%$ & $52.1 \%$ & \\
\hline & \multirow{2}{*}{ Impaired } & No. & 1 & 46 & \\
\hline & & $\%$ & $7.7 \%$ & $47.9 \%$ & \\
\hline \multirow{4}{*}{ Motor exam } & \multirow{2}{*}{ Intact } & No. & 13 & 87 & \multirow{4}{*}{0.304} \\
\hline & & $\%$ & $100.0 \%$ & $90.6 \%$ & \\
\hline & \multirow{2}{*}{ Impaired } & No. & 0 & 9 & \\
\hline & & $\%$ & $0.0 \%$ & $9.4 \%$ & \\
\hline \multirow{6}{*}{ Tinnel's sign } & \multirow{2}{*}{ No } & No. & 9 & 6 & \\
\hline & & $\%$ & $69.2 \%$ & $6.2 \%$ & \\
\hline & One & No. & 2 & 40 & \multirow{4}{*}{$0.0001 *$} \\
\hline & hand & $\%$ & $15.4 \%$ & $41.7 \%$ & \\
\hline & \multirow{2}{*}{$\begin{array}{l}\text { Both } \\
\text { hands }\end{array}$} & No. & 2 & 50 & \\
\hline & & $\%$ & $15.4 \%$ & $52.1 \%$ & \\
\hline \multirow{6}{*}{ Phalen's test } & \multirow{2}{*}{ No } & No. & II & 27 & \multirow{6}{*}{$0.0001 *$} \\
\hline & & $\%$ & $84.6 \%$ & $28.1 \%$ & \\
\hline & One & No. & 2 & 31 & \\
\hline & hand & $\%$ & $15.4 \%$ & $32.3 \%$ & \\
\hline & \multirow{2}{*}{$\begin{array}{l}\text { Both } \\
\text { hands }\end{array}$} & No. & 0 & 38 & \\
\hline & & $\%$ & $0.0 \%$ & $39.6 \%$ & \\
\hline \multirow{6}{*}{ Muscle wasting } & \multirow{2}{*}{ No } & No. & 13 & 89 & \multirow{6}{*}{0.389} \\
\hline & & $\%$ & $100.0 \%$ & $92.7 \%$ & \\
\hline & One & No. & 0 & 5 & \\
\hline & hand & $\%$ & $0.0 \%$ & $5.2 \%$ & \\
\hline & \multirow{2}{*}{$\begin{array}{l}\text { Both } \\
\text { hands }\end{array}$} & No. & 0 & 2 & \\
\hline & & $\%$ & $0.0 \%$ & $2.1 \%$ & \\
\hline
\end{tabular}

Table 5 Relation between pain scale and motor distal latency

\begin{tabular}{|c|c|c|c|c|}
\hline \multirow{3}{*}{ Pain scale } & \multicolumn{4}{|c|}{ Motor distal latency } \\
\hline & \multicolumn{2}{|c|}{ Normal } & \multicolumn{2}{|c|}{ Abnormal } \\
\hline & No. & $\%$ & No. & $\%$ \\
\hline No & 9 & 12.2 & I & 2.9 \\
\hline Mild & 6 & 8.1 & 4 & 11.4 \\
\hline Moderate & 24 & 32.4 & 4 & 11.4 \\
\hline Severe & 35 & 47.3 & 26 & 74.3 \\
\hline Total & 74 & 100 & 35 & 100 \\
\hline $\mathrm{P}$ & $0.0025^{*}$ & & & \\
\hline
\end{tabular}

Table 6 Relation between pain scale and peak median sensory

\begin{tabular}{lllll}
\hline \multirow{2}{*}{ Pain scale } & \multicolumn{3}{l}{ Peak median sensory } \\
\cline { 2 - 5 } & \multicolumn{2}{l}{ Normal } & \multicolumn{2}{l}{ Abnormal } \\
\cline { 2 - 5 } & No. & $\%$ & No. & $\%$ \\
\hline No & 8 & 61.5 & 2 & 2.1 \\
Mild & 3 & 23.1 & 7 & 7.3 \\
Moderate & 2 & 15.4 & 26 & 27.1 \\
Severe & 0 & 0.0 & 61 & 63.5 \\
Total & 13 & 100.0 & 96 & 100.0 \\
P & $0.001 *$ & & \\
\hline
\end{tabular}


Prolonged peak median sensory latency was significantly correlated with numbness $\mathrm{p}=0.0001$, severity of pain $\mathrm{p}=0.001$, Impaired sensory exam $\mathrm{p}=0.005$, positive Tinel's sign for either one or both hands $\mathrm{p}=0.0001$, positive Phalen test of one or both hands $\mathrm{p}=0.0001$

\section{Discussion}

Carpal tunnel syndrome commonly affects middle age group, predominantly women. ${ }^{25,26}$ Similar to the literature, the mean age of patients in this study was 57.7 and women represented the majority of the patients $83 \%$.

All the included patients with signs and symptoms suggestive of CTS have shown positive electrophysiological studies, even with comparative techniques.

This is in contrast to Gunnarsson LG et al. ${ }^{27}$ who reported high specificity of electrophysiological studies but less sensitivities as they had false negative diagnostic tests in $13 \%$ of their patients.

This may be because they were not using the comparative techniques for those patients with normal routine NCS to detect very mild CTS.

Tinel signs and Phalen test are commonly used to complement the clinical diagnosis of CTS. Their sensitivity and specificity are variable. Tinel 's sign is associated with sensitivity $23 \%-67 \%$ and specificity $55 \%-100 \%{ }^{11,13-17}$ While Phalen test reported sensitivity range from $10 \%-91 \%$ and specificity between $33 \%$ and $100 \%{ }^{11,12,16,17-20}$

Revising literature, a study investigating the prevalence of CTS in women in Iran, Tinel's sign was present in $58.9 \%$ and Phalen test in $50.9 \%{ }^{28}$ In another study Tinel and Phalen were positive in $71.1 \%$ and $82.2 \%$ respectively. ${ }^{28,29}$ In this study, Tinel's sign was positive in $86.2 \%$ of patients and Phalen was positive in $65.2 \%$.

Pekel NB et al. ${ }^{25}$ reported that Tinel sign and Phalen test were positively correlated with CTS in both right and left hand. They used the distal median motor latency and sensory median amplitude. ${ }^{25}$

In this study abnormal distal median motor latency was significantly correlated with bilateral Tinel's sign and bilateral Phalen, whereas Peak median sensory latency was significantly correlated with both Tinel's sign and Phalen test whether for one or both hands.

Pain is reported by $74 \%$ of patients with CTS while paresthesia reported by $50 \% .{ }^{30}$ In this study, pain was reported using VAS in $90.8 \%$ of patients out of them $56 \%$ were having severe pain. Numbness was reported by $87.2 \%$ of the studied patients.

In this study, the severity of pain was significantly correlated with prolonged peak median sensory latency as well as abnormal distal motor latency. While numbness was only correlated with prolonged peak median sensory latency.

Similarly, Pekel NB et al. ${ }^{25}$ found positive correlation between the severity of pain and the severity of CTS as detected by electrophysiological tests. ${ }^{25}$

In the previous studies sensory loss was positively correlated with CTS. ${ }^{25}$ Pavesi G et al. ${ }^{31}$ found highly significant correlation between sensory deficit (hypoesthesia to tough and/or pain ) and the amplitude of sensory action potential. ${ }^{31}$

In this study impaired sensory exam was significantly correlated with both prolonged peak median sensory latency and abnormal distal motor latency.

Also, in this study, the presence of motor deficit was only significantly correlated with abnormal distal motor latency. Pavesi G et al. ${ }^{31}$ found similar result. ${ }^{31}$

In this study, unilateral and bilateral thenar muscle atrophy was significantly correlated with abnormal distal motor latency.

Similar results were found by Ertekinc et al. ${ }^{26}$ and Pekel NB et al. ${ }^{25}$ In contrast, Ozdolap et al. ${ }^{32}$ reported no relation between thenar atrophy and electrophysiological findings and they reported that the reason of that is the low number of their patients.

In this study, the electrophysiological testing revealed pure sensory median neuropathy in $59.64 \%$ while sensory motor median neuropathy in $40.3 \%$ of patients. The majority of the studied patients had demyelinating pathology $91.7 \%$ and only $8.3 \%$ having secondary axonal changes. This demonstrates the importance of thorough NCS including the comparative studies to detect the very mild cases of CTS who having the clinical symptoms and signs of CTS and have normal routine NCS, since the sensory pathology constituting most of patients.

In contrast Vahdatpour et al. ${ }^{33}$ reported that the most specific test is distal motor latency (93\%) while the most sensitive was median nerve terminal latency index $82 \%$.

\section{Conclusion}

Electrophysiological tests including comparative median nerve studies confirm the clinical diagnosis of CTS. Highly significant correlation was found between subjective and objective sensory manifestation and peak median sensory latency. While distal motor latency was significantly correlated with severe pain, only bilateral positive Tinel's sign and Bilateral Phalen test and the objective sensory and motor deficit

\section{Acknowledgement}

None.

\section{Conflict of interest}

The Authors declare no conflict of interests.

\section{References}

1. Aroori S, Spence RAJ. Carpal tunnel syndrome. Ulster Med J. 2008;77(1):6-17.

2. Tanaka S, Wild DK, Seligman PJ, et al. The US prevalence of selfreported carpal tunnel syndrome: 1988 National Health Interview Survey data. Am J Public Health. 1994;84(11):1846-8.

3. Atroshi I, Gummesson C, Johnsson R, et al. Prevalence of carpal tunnel syndrome in a general population. JAMA. 1999;282(2):153-8.

4. Krom MC, Knipschild PG, Kester AD, et al. Carpal tunnel syndrome: prevalence in the general population. J Clin Epidemiol. 1992;45(4):373-

5. Stevens JC, Sun S, Beard CM, et al. Carpal tunnel syndrome in Rochester, Minnesota, 1961 to 1980. Neurology. 1988;38(1):134-8.

6. Einhorn N, Leddy JP. Pitfalls of endoscopic carpal tunnel release. Orthop Clin North Am. 1996;27(2):373-80. 
7. Ferry S, Pritchard T, Keenan J, et al. Estimating the prevalence of delayed median nerve conduction in the general population. $\mathrm{Br} J$ Rheumatol. 1998;37(6):630-5.

8. Prick JJ, Blaauw G, Vredeveld JW, et al. Results of carpal tunnel release. Eur J Neurol. 2003;10(6):733-6.

9. Mondelli M, Giannini F, Giacchi M. Carpal tunnel syndrome incidence in a general population. Neurology. 2002;58(2):289-94.

10. Hoffmann P, Buck GD, Lubahn JD. The Hoffmann-Tinel sign. 1915. J Hand Surg. 1993;18(6):800-5.

11. Buch JN, Foucher G. Correlation of clinical signs with nerve conduction tests in the diagnosis of carpal tunnel syndrome. $J$ Hand Surg. 1994;19(6):720-4.

12. Katz JN, Larson MG, Sabra A, et al. The carpal tunnel syndrome: diagnostic utility of the history and physical examination findings. Ann Intern Med. 1990;112(5):321-7.

13. Kuhlman KA, Hennessey WJ. Sensitivity and specificity of carpal tunnel syndrome signs. Am J Phys Med Rehabil. 1997;76(6):451-7.

14. Kuschner SH, Ebramzadeh E, Johnson D, et al. Tinel's sign and Phalen's test in carpal tunnel syndrome. Orthopedics. 1992;15(11):1297-302.

15. Phalen CM. The carpal-tunnel syndrome. Seventeen years' experience in diagnosis and treatment of six hundred fifty-four hands. J Bone Joint Surg Am. 1966;48(2):211-28.

16. Gerr F, Letz R, Harris AD, et al. Sensitivity and specificity of vibrometry for detection of carpal tunnel syndrome. J Occup Environ Med. 1995;37(9):1108-15.

17. Golding DN, Rose DM, Selvarajah K. Clinical tests for carpal tunnel syndrome: an evaluation. Br J Rheumatol. 1986;25(4):388-90.

18. De Smet L, Steenwerckx A, Van den BG, et al. Value of clinical provocative tests in carpal tunnel syndrome. Acta Orthop Belg. 1995;61(3):177-82.

19. Kaufman MA. Differential diagnosis and pitfalls in electrodiagnostic studies and special tests for diagnosing compressive neuropathies. Orthop Clin North Am. 1996;27(2):245-52.

20. Bruske J, Bednarski M, Grzelec H, et al. The usefulness of the Phalen test and the Hoffmann-Tinel sign in the diagnosis of carpal tunnel syndrome. Acta Orthop Belg. 2002;68(2):141-5.

21. Jablecki CK, Andry MT, Floeter MK, et al. Practice parameter: Electrodiagnostic studies in carpal tunnel syndrome. Report of ther American Association of Electrodianostic Medicine, American Academy of Neurology and The American Academy of Physical Medicine and Rehabilitation. Neurology. 2002; 58(11):1589-92.
22. Rempel D, Evanoff B, Amadio PC, et al. Consensus criteria for classification of carpal tunnel syndrome in epidemiologic studies. Am J Public Health. 1998;88(10):1447-51.

23. Katz JN, Larson MG, Sabra A, et al. The carpal tunnel syndrome: diagnostic utility of the history and physical examination findings. Ann Intern Med. 1990;112(5):321-7.

24. Preston DC, Shapiro B. Median neuropathy at wrist. Chapter 17 in Electromyography and neuromuscular disorders: clinicalelectrophysiologic correlation, 3rd ed. 2013:267-288.

25. Pekel NB, Senol PN, Yildiz D, et al. The diagnostic efficacy of clinical findings and electrophysiological studies in carpal tunnel syndrome. The European Research Journal. 2016.

26. Ertekin C. Santral PEMG Anatomi-Fizyoloji-Klinik. Izmir: Meta Basim Matbacilik Hizmetleri, 2006;403-27.

27. Gunnarsson LG, Hellstrand AP, Leissner P, et al. The diagnosis of carpal tunnel syndrome; Sensitivity and specificity of some clincal and electrophysiological tests. Journal of hand surgery. 1997;22(1):34-37.

28. Yazdanpanah P, Aramesh S, Mousavizadeh A, et al. Prevalence and severity of carpal tunnel syndrome in women. Iran J Public Health. 2012;41:105-10.

29. Eftekharsadat B, Babaei GA, Habibzadeh A. The Efficacy of 100 and 300 $\mathrm{mg}$ Gabapentin in the treatment of carpal tunnel syndrome. Iran J Pharm Res. 2015;14:1275-80.

30. Jesus FAG, Nascimento BF, Amorim MC, et al. Comparative study between physical examination, electroneuromyography and ultrasonography in diagnosing carpal tunnel syndrome. Rev Bras Ortop. 2014;49:446-51.

31. Pavesi G, Oliveri MF, Misk A, et al. Clinical-Electrophysiological correlations in the carpal tunnel syndrome. The Italian journal of Neurological Sciences. 1986;7(1):93-96.

32. Ozdolap S, Sarikaya S, Sumer M, et al. Relationship between clinical findings and electrodiagnostic studies in patient with carpal tunnel syndrome. Turk J Phys Med Rehab. 2005;51:134-7.

33. Vahdatpour B, Khosrawi S, Chatraei M. The role of median nerve terminal latency index in the diagnosis of carpal tunnel syndrome in comparison with other electrodiagnostic parameters. Adv Biomed Res. 2016;5:110. 